\title{
Nuevos Espacios Urbanos Para Nuevas Tendencias: Medicina Complementaria y Alternativa y Ciudades Medias Globales
}

\author{
Antonia Ramírez \\ Rosalía Martínez \\ Universidad Pablo de Olavide, Sevilla \\ Miguel A. Márquez \\ Universidad Nacional Autónoma de México
}

doi: 10.19044/esj.2017.v13n5p526 URL:http://dx.doi.org/10.19044/esj.2017.v13n5p526

\begin{abstract}
Complementary and alternative medicine refers to the use and benefit of non-allopathic medicines, which is presently increasing in Western societies. This study, on one hand, shows the presence and the form that this new fashion among the population adopts. On the other hand, it shows the spatial distribution of the tendency in CAM. This refers to its distribution according to neighborhoods and metropolitan territories. For this purpose, the city of Seville, Spain, a middle European city present in the network of global cities, has been selected for this study. To show this sociological reality, quantitative methodology has been conducted within two years beginning from 2013 to 2014. The database that was created provided information about the offer of the CAM, specifically 100 different practices related with the complementary and alternative medicine of 450 Centers and professionals. This is with a total of 1338 number of answers.
\end{abstract}

Keywords: Types of Complementary and Alternative Medicine, Urban Areas, Fashion, European Global City.

\section{Resumen}

La medicina complementaria y alternativa (CAM en inglés) se refiere al uso y disfrute de medicinas no alopáticas, las cuales están cada día más presentes en las sociedades occidentales. Este trabajo muestra, por un lado, la presencia y la forma que adopta esta nueva tendencia entre la población. Por otro lado, la distribución espacial de la tendencia en CAM, es decir, su distribución según barrios y territorios metropolitanos. Para ello se ha seleccionado la ciudad de Sevilla, España, ciudad europea media, presente en la red de ciudades globales. 
Para mostrar esta realidad sociológica se ha realizado trabajo de campo con metodología cuantitativa durante dos años, de 2013 a 2014. La base de datos creada da información sobre la oferta de CAM, en concreto 100 diferentes prácticas en salud y bienestar en 450 centros y profesionales, con un total de 1338 respuestas.

Palabras clave: Tipos de Medicina Complementaria y Alternativa, Espacios Urbanos, Tendencias, Ciudad Europea Global.

No describimos el mundo, como mucho hacemos mapas para ayudar, modestamente, a no perdernos. [Emilio Lamo de Espinosa, Nómadas, 11(1), 2005, p.11].

\section{Introducción}

La medicina integrativa es la acepción que parece estar tomando fuerza frente a otros conceptos como medicina complementaria y alternativa, y medicina complementaria y tradicional. Estas acepciones, en cualquier caso, se refieren al uso y disfrute de medicinas no alopáticas y que están presentes en las sociedades occidentales cada día con mayor fuerza. Estas disciplinas o medicinas se caracterizan principalmente por una visión holística en la relación de la persona con el medio: cualquier alteración en los patrones de salud ha de observarse desde la integración del individuo en la totalidad, con el objeto de conseguir una vida saludable y armoniosa. En Sevilla, la medicina complementaria y alternativa (MCA) se observa como una tendencia surgida en la década de los 80 y 90 y difundida a lo largo de la década del 2000 en adelante. Este trabajo muestra, por un lado, la presencia de esta tendencia en la ciudad de Sevilla. Por otro lado, como territorio presente en la red de ciudades globales, se muestra la presencia de esta tendencia de acuerdo a los espacios que configuran la metrópoli: los territorios de la ciudad, propiamente dicha, y la relación de ésta con las coronas metropolitanas.

Para mostrar el mapa de las tendencias en MCA, se ha realizado una recogida de información a partir de técnicas cuantitativas. Se ha recopilado información durante dos años para elaborar una base de datos de la oferta de actividades relacionadas con la medicina complementaria y alternativa en la ciudad de Sevilla y el área metropolitana ${ }^{77}$. La base de datos recoge, por tanto, la oferta de las actividades desarrolladas en esta ciudad ${ }^{78}$. Además, se han localizado bases de datos secundarias para caracterizar los rasgos de la población y área metropolitana de Sevilla, principalmente del Instituto de

77 Trabajo realizado dentro del Proyecto de Investigación Salud y Bienestar Personal (PPI0906), financiado por la Universidad Pablo de Olavide.

78 La metodología seguida para la elaboración de la base de datos puede consultarse en el Anexo 1. 
Estadística y Cartografía de Andalucía (IECA) y del Ayuntamiento de Sevilla.

En la lógica de análisis sociológico (Elster, 2003; Boudon, 1981), el trabajo se centra en mostrar el hecho social y, en la medida de lo posible, algunas pautas del contexto donde se desarrolla; y en menor medida en las oportunidades $^{79}$ y en la formación de preferencias ${ }^{80}$. Por tanto, la oferta de actividades $^{81}$ en medicina complementaria y alternativa y su expresión en el territorio centran el análisis.

\section{Tendencias en Medicina Complementaria y Alternativa}

De acuerdo con la sociología de las tendencias, el objeto se constituye como el elemento base del que parte cualquier descripción del proceso (Sproles, 1974). En este caso el objeto lo constituye la MCA, es decir, un conjunto de prácticas que se ofertan como producto en el mercado, y que surgen y se difunden por la convergencia de los gustos colectivos. En el caso de esta medicina, las personas empiezan a interesarse por acudir a profesionales que disminuyan sus dolencias gracias al uso de medicinas no convencionales, y que, en la mayoría de los casos, ejercen su actividad fuera del sistema público de salud ${ }^{82}$. La reducción o eliminación del dolor por estos profesionales se produce, en algunos casos, gracias a la inserción de agujas de acupuntura en determinadas partes del cuerpo; en otros casos, algunas enfermedades empiezan a sanar sin necesidad de operaciones quirúrgicas, a partir de la manipulación en determinadas zonas del cuerpo por un profesional de la osteopatía; algunas personas aumentan el nivel de la conciencia y el control mental, y una mejora en el bienestar bio-psico-social, gracias a la práctica de la meditación o del yoga.

Estas prácticas hablan de una medicina que surge como una ruptura a la forma de medicina presente hasta el momento en la sociedad occidental ${ }^{83}$.

79 Para las oportunidades véase Ramírez y Márquez, (2017).

80 Para la formación de las preferencias véase Ramírez, (2016).

81 La medicina complementaria y alternativa se la suele nombrar con una variedad de términos, como son actividades, prácticas, disciplinas, medicinas, y terapias. Esta miríada de términos con variaciones sutiles en el significado, tanto lingüístico como simbólico, son una expresión propiamente dicha del surgimiento de esta tendencia. En cualquier caso, este debate no es objeto de este trabajo, y sirva aquí señalar que tratarán de usarse de la forma más adecuada posible.

$82 \quad$ Puede que estos profesionales sean, también, profesionales del sistema público de salud, como médicos o enfermeros, que se han formado también en técnicas de MCA. Puede, como es el caso de la Unidad del Dolor del Hospital Virgen del Rocío, de Sevilla, que alguna técnica de MCA se desarrolle en un Centro Público de Salud. La tendencia que se presenta en estas páginas muestra su difusión cada vez mayor. Aun así, cerca del $90 \%$ de la actividad se desarrolla desde la oferta privada (Ramírez, 2016).

83 La medicina complementaria y alternativa se caracteriza por su acercamiento holístico. Lo holístico, o la totalidad, 
En este momento, en este espacio de emergencia, siguiendo a Foucault (1979), se hacen presentes los dos actores de la escena, ocupando sus respectivos espacios en el escenario, el alopático y el alternativo. Además, entre 2012 y 2015, probablemente asistamos al tipping point, o momento de máxima difusión de esta tendencia, pues desde las primeras asociaciones y escuelas a principios de los 80 , su crecimiento y expansión se desarrolla de forma tímida pero continua desde mediados de los 90 hasta nuestros días, donde en los últimos años su crecimiento ha sido sorprendente, tanto en los espacios privados, como en las áreas de deportes y cultura repartidos entre los barrios (Ramírez, 2016). La gráfica 1 permite mostrar parte de esta 'escena'. Recoge las 25 primeras actividades ofertadas, de un total de 94 actividades recogidas en la base de datos. Estas 94 actividades se desarrollan en alrededor de 450 centros o profesionales, desarrollando éstos más de una actividad, en total cerca de 1340 actividades se han recogido en el área metropolitana de Sevilla. Es decir, en un centro o una consulta puede desarrollar una, dos o varias de las actividades que se muestran en el listado de actividades del Anexo 2. Por lo que podría decirse que existe una diversificación de hasta tres actividades por profesional o empresario. Así, por ejemplo, una persona o un centro que imparta clases de yoga, probablemente también incluirá prácticas de meditación, prácticas de reiki, algún tipo de masaje, o terapia. Del mismo modo, un profesional en su consulta de naturopatía, puede, además de realizar prácticas de acupuntura, orientar sobre algún medicamento homeopático, o la administración de algún tipo de remedio floral. De igual modo, un osteópata, además de realizar la práctica de manipulación determinada, podrá aplicar reflexología o kinesiología.

La presencia de esta multitud y diversificación de actividades parece estar mostrando una oferta espectacular de espacios y personas relacionadas con la MCA. Según se observa en la gráfica, las actividades más ofertadas coinciden con las más demandas (Observatorio Terapias Naturales, 2008): El yoga y la acupuntura. También están muy presentes otra serie de actividades, como las prácticas de manipulación - el quiromasaje o la osteopatía -; sistemas integrales como la medicina homeopática y la naturopatía;

incluye al individuo en el espacio infinito, y en todos los procesos y realidades presentes en ese espacio. La conciencia humana, no obstante, elabora conceptualizaciones dimensionales de esa totalidad, parcelando la misma, a fin de poder explicarla. Así, lo holístico incorpora lo material, lo mental, lo emocional, lo comunicativo, lo social; lo etérico o sutil junto con lo reticular o físico. En cualquier caso, la totalidad incluye esas dimensiones generadas por el primitivo intelecto humano, aunque sería la fusión y expresión de las mismas en la naturaleza humana el objeto del acercamiento holístico (puede consultarse, entre otros Capra, 1984). 
actividades sobre la base de la conciencia - la meditación y la biodanza-; y técnicas sobre la base de la energía - el reiki y el trabajo con chakras.

Gráfica 1. Oferta de actividades medicina complementaria y alternativa. Sevilla, 2013-14

$\left(\mathrm{N}^{\circ}\right.$ de respuestas $\left.=1338\right)$

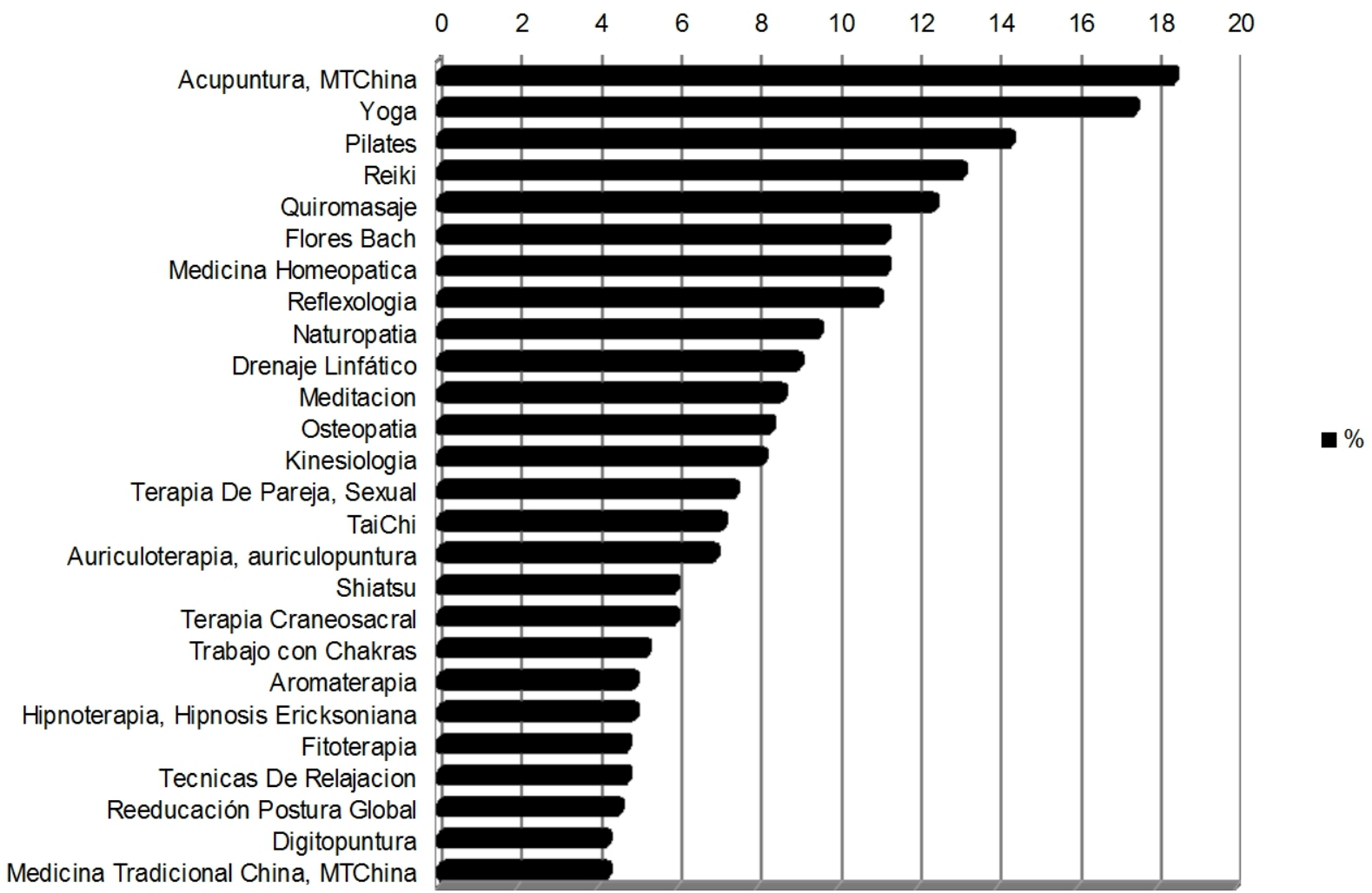

Fuente: Elaboración propia, 2016

En resumen, la medicina complementaria y alternativa, como nuevo producto, se presenta frente a la medicina alopática ocupando un espacio en el escenario de las medicinas y la salud. Entre los años 2012-2015 asistimos al momento de máxima expresión de la oferta, con alrededor de 1350 expresiones de 94 actividades, en aproximadamente 445 centros o profesionales, con acupuntura, yoga, pilates, reiki y quiromasaje como las 5 primeras actividades más ofertadas.

\section{La Funcionalidad de la Tendencia}

Las cualidades y los rasgos que caracterizan a la MCA permiten hablar de la funcionalidad de esta tendencia. Tanto las tendencias funcionales como no funcionales emergen por convergencia de gustos 
colectivos, no obstante, las primeras están asociadas a la evolución del contexto, es decir, el marco social de la época permite entender la evolución de la tendencia ${ }^{84}$. Además, la tendencia funcional responde a una utilidad o propósito, frente a las tendencias no funcionales (Erner, 2013). Y esta utilidad o propósito, para el caso de la MCA, parecería responder a modificaciones sociales, pues, como se viene señalando, incorpora nuevas formas de entender la salud. Además, de forma indirecta, también podría afectar al sistema económico, al generar nuevos 'nichos de riqueza'.

Para presentar esta tendencia y aclarar un poco más su funcionalidad desde un punto de vista social, o sociológico ${ }^{85}$, se ha realizado una clasificación de la MCA. La clasificación se elabora a partir de definiciones teóricas de los diferentes tipos de medicina, y se contrasta con informes de profesionales, tanto los emitidos desde la administración pública, como los realizados con expertos en este ámbito. Señalar la gran diversidad que hay en este tipo de prácticas, como se ha comentado más arriba, 94 actividades se han recogido en esta investigación, y no son las únicas, pues el Informe sobre Terapias Naturales, del Ministerio de Sanidad (2011) contempla más, y no todas coinciden con las recogidas en este estudio.

La clasificación incluye el conjunto de actividades, tratando de entender la dimensión que subyace a estas para poder incluirlas en un criterio clasificatorio u otro. Sobre la base de esa información se ha generado una con seis categorías ${ }^{86}$. Esta clasificación trata de cumplir con los criterios de exhaustividad y exclusión propia de las clasificaciones empíricas en ciencias sociales (Bartolini, 1986). No obstante, la peculiaridad o particularidad de estas actividades hace difícil cumplir de forma pura estos criterios. Por ejemplo, los sistemas integrales pueden incorporar actividades de alguna otra

84 Las tendencias no funcionales se desarrollan por la evolución de los gustos, de las formas y los colores, sin que hasta el día de hoy exista una teoría que permita entender por qué la elección de esa forma y color en un contexto social determinado: la moda hipster y las blusas con mariposas mostradas en los escaparates londinenses, berlineses o sevillanos, tan de moda cuando se escriben estas líneas, obedecen a una no funcionalidad, e igual que son ahora tendencia, podían haberlo no sido o serlo en otros contextos socio-histórico. En el caso de la tendencias funcionales Chronos,el dios del Tiempo Universal, ayuda a entender su emergencia, en el segundo caso, no funcionales, Chronos juega con los estilistas y los coolhunters.

85 Siguiendo a Lamo de Espinosa, la sociología es una herramienta en manos de la etnosociologia, y no a la inversa. La realidad social hace uso del conocimiento sociológico para re-cambiarse (Lamo de Espinosa, 2005).

86 La clasificación que se presenta a continuación parte de 1) la clasificación realizada por el National Center for Complementary and Alternative Medicine (NCCAM), de Estados Unidos, 2) del análisis realizado, en base a esa clasificación, en el Informe sobre Terapias Naturales del Ministerio de Sanidad, Política Social e Igualdad, en el año 2011, y 3) de la Resolución de 12 de agosto de 2013, del Ministerio de Empleo y Seguridad Social que publica el I Convenio Colectivo Estatal de Naturopatía y Profesionales Naturópatas. 
categoría, pero ello no implica que estas actividades no puedan desarrollarse de forma autónoma al sistema integral que la incluye. Así, algunas técnicas de manipulación como la auriculoterapia, propias de la medicina tradicional China, se desarrollan también por otros profesionales que no ejercen la profesión de médico basada en esta tradición. Parecería, por tanto, inadecuado excluir estas actividades de la clasificación, pese a que estén, podríamos decir, contenidas de forma implícita en alguna actividad. Por otro lado, las técnicas sobre la base de la conciencia pueden afectar al campo energético de la persona. La meditación, por ejemplo, tiene como resultado, entre otros, armonizar el campo etérico o energético, si bien no actúa directamente sobre el mismo, a diferencia de las técnicas sobre la base de la energía, que si lo hacen. En este caso, el criterio clasificatorio no excluye a la meditación de ambas categorías, no obstante, sitúa a la actividad en aquella que con más fuerza se expresa.

La gráfica 2 presenta la distribución de la oferta de actividades de MCA de acuerdo a la clasificación ${ }^{87}$. Para el caso de la metrópolis sevillana, se puede observar una mayor presencia de unas actividades sobre otras. Las prácticas de manipulación y basadas en el cuerpo, centradas en el movimiento y/o manipulación de una o más partes del cuerpo, son las que se erigen como líder entre la oferta de las actividades, suponiendo un 34,5\% del total de las actividades. Es decir 1/3 de las actividades que se oferta en el área metropolitana se orientan principalmente a que "nos toquen”. Bien sea a través de masajes, como el masaje balinés, el de piedras calientes, el masaje sueco; bien sea a través de técnicas que tratan de modificar las estructuras músculo- esqueléticas: quiromasaje, osteopatía, percutor estructural, reestructuración fascial, técnica metamórfica; bien sea mediante la manipulación en zonas del cuerpo, que tiene su impacto, como reflejo, en determinados órganos del cuerpo humano: reflexología, auriculoterapia, digitopuntura, y reflexokinesia.

87 En el Anexo 3 pueden consultarse de forma pormenorizada las actividades que se han incluido en uno u otro criterio. 
Gráfica 2. Clasificación de actividades de medicina complementaria y alternativa. Sevilla 2013-14.

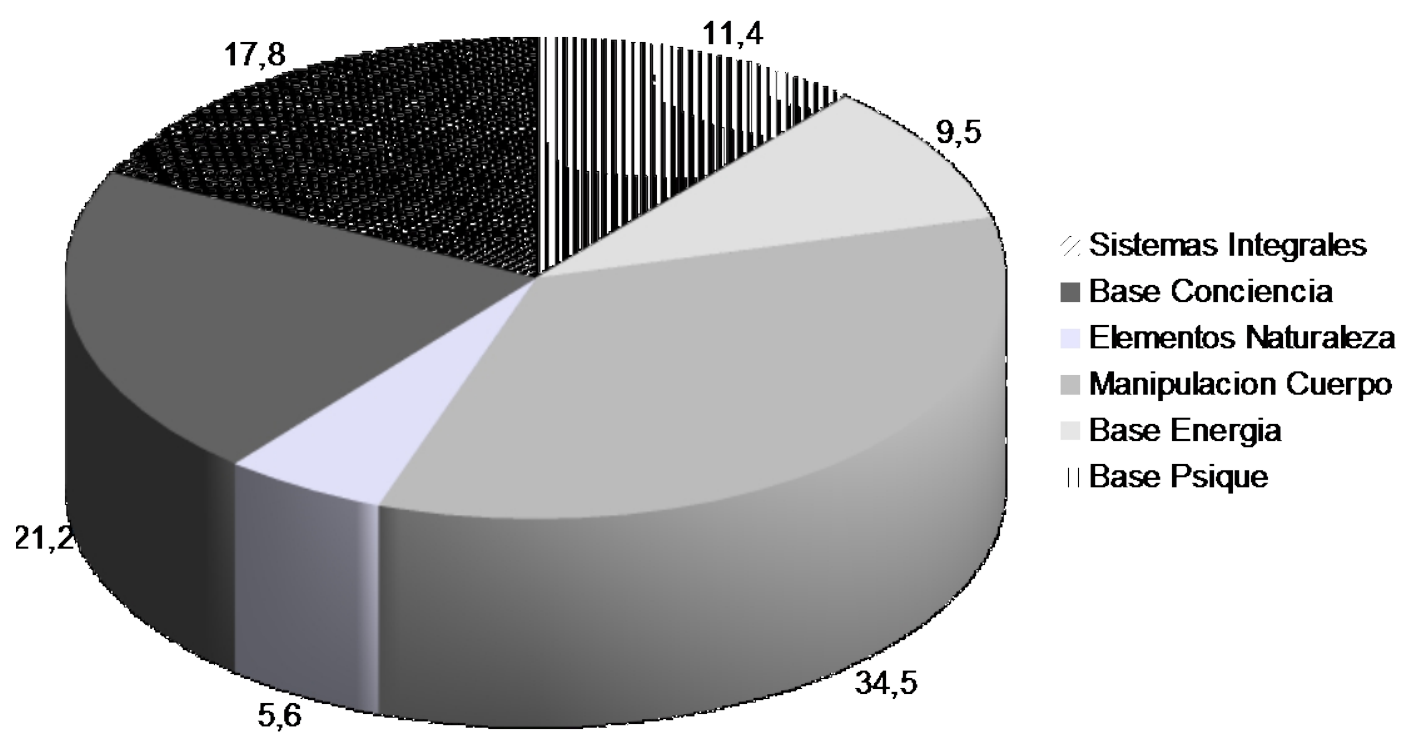

Fuente: Elaboración propia, 2016

El siguiente grupo de actividades ofertadas son aquellas asociadas a las técnicas sobre la base de la conciencia (mente-cuerpo), con algo más de un $21 \%$ de la oferta acumulada en esta categoría, 1/5 del total de la misma. Estas técnicas se basan en el control mental, en la toma de conciencia de la persona desde la interacción de mente-cuerpo. El trabajo con las emociones también es importante, como elemento que articula la relación mente-cuerpo. Respiración holotrópica, sofrología, danzaterapia y yoga se caracterizarían por el movimiento del cuerpo, frente a metamedicina, meditación o técnicas de relajación, donde el cuerpo, aún presente, no realiza necesariamente movimiento.

En tercer lugar, encontramos la oferta de sistemas integrales o completos, que son aquellos que poseen un conocimiento completo de teoría y práctica, y que representa el $17,8 \%$. En esta categoría se encontrarían actividades tales como la naturopatía y la medicina homeopática, ambas con una gran tradición en la cultura occidental; La medicina ayurveda, la medicina chamánica, o la medicina tradicional china se encuentra también en este grupo, con fuerte presencia en los países de origen y con cada día mayor relevancia en los sistemas de salud occidentales (OMS, 2013).

A este grupo le sigue las técnicas con base en la psique y patrones mentales, representando $11,5 \%$ del total de la oferta. Son técnicas orientadas al campo de la psique y de la personalidad, al cambio en patrones mentales. 
Aunque pertenecientes al campo de la psicología, estas técnicas suelen aplicarse desde la visión holística de la persona, proponiendo otro acercamiento al convencional. Además de la hipnosis, incluiría las "nuevas psicologías" -PSYCH-K, bioenergética, logoterapia, sinergética, etc.-; también estarían aquí las terapias que desde la creatividad tratan de modificar patrones metales - musicoterapia, risoterapia...-. Además, un grupo de actividades con base en nuestro potencial mental y nuestra capacidad para modificarlo -Programación Neurolingüística (PNL), Coaching, inteligencia emocional, constelaciones familiares, y entre otros.

También cercano al 10\% (9,5\%) se encontraría la oferta relativa a técnicas sobre la base de la energía. Focalizadas en el campo biomagnético o bioelectromagnético, basan su conocimiento en la armonización del campo energético que rodea el cuerpo físico o reticular. Algunas de ellas con la necesidad de un profesional para su administración o aplicación, y otras con un nivel de autonomía relativo en su aplicación una vez realizada la formación adecuada. Así, por ejemplo, sintergética, sanación reconectiva o par biomagnético entrarían dentro de la primera categoría, mientras que reiki y trabajo con chakras lo harían dentro de la segunda. La oferta aquí, por tanto, se centra en actividades cuyo objetivo es armonizar el campo energético, no visible, de la persona, de localizar vacíos o ausencias de energía, o densidades energéticas desproporcionadas, y llevarlas a un estado armonioso.

Las prácticas biológicas y con elementos de la naturaleza, por último, suponen un $5,6 \%$ de la oferta. Actividades que emplean las sustancias que se encuentran en la naturaleza y con propiedades terapéuticas, es decir, remedios para tratamiento de enfermedad. En su mayoría son tratamientos que se aplican o se desarrollan sin necesidad de administración por vía oral, como puede ser la fangoterapia, aquabalance, hidroterapia..., aunque los hay también administrados por vía oral. Entre ellos, la fitoterapia, u otras técnicas que se basan en el tipo de alimento que se ingiere y la forma de ingerirlo, como la macrobiótica y la dietoterapia. También se incluyen en esta categoría la administración por vía cutánea, como la apiterapia. Muchas de estas prácticas son las que tradicionalmente se desarrollan en los balnearios, con tanta tradición en nuestra península, donde una dieta y sesiones de hidroterapia y fangoterapia constituyen la esencia para enfermedades muy variadas, desde reuma a asma.

Como resumen, se puede decir que la MCA es una tendencia funcional al sistema, y que su funcionalidad o utilidad descansa sobre todo en la aportación que hace al elemento social, y en concreto, al cambio social que parece se está operando en la nueva forma de entender la salud y la enfermedad. Este documento establece un mapa de esa utilidad desde la visión de la oferta de actividades, es decir, desde lo que un grupo de 
personas, profesionales y empresarios, trata de establecer como tendencia frente a otras formas de medicina. La utilidad u oportunidad de la tendencia, además, puede diferenciarse según el ámbito o aspecto que más se resalta en la actividad, estableciéndose seis categorías en atención a 1) la base de la conciencia, 2) la base de la energía, 3) la base de los patrones mentales, 4) las prácticas de manipulación, 5) los elementos en la naturaleza, y 6) los sistemas integrales o completos.

\section{Sevilla Ciudad de Tercera Categoría en el Ranking de Ciudades Globales}

El área metropolitana de Sevilla comprende alrededor de 1.500.000 habitantes ${ }^{88}$, es una de las aglomeraciones urbanas del sur de Europa que mayor afluencia de turismo recibe a lo largo del año, tanto de turismo de corta como de larga duración. En Sevilla se encuentra la sede del gobierno regional de la Comunidad Autónoma de Andalucía, siendo, además, la capital de la misma. En Sevilla es importante el flujo de información y la actividad empresarial, y es un espacio de expresión cultural y artística nacional e internacional. Sevilla tiene una red de infraestructuras y comunicaciones por red fluvial, área y terrestre que permite el flujo diario de un importante intercambio de mercancías y pasajeros. Estas son algunas de las características de las ciudades globales, conocidas con ese término para designar aquellas ciudades que forman parte del proceso de la globalización, en su dimensión económica, por la importancia y movilidad de sus flujos financieros, y por constituir espacios para la expresión del arte y la cultura de vanguardia (Sassen, 1991, 1994; Beaverstock \& Taylor, 2000). Además, en las ciudades globales se concentra una población que desarrolla profesiones altamente cualificadas, que suponen un importante ingreso de recursos para la ciudad, y que suelen ser progresistas socialmente -tolerancia hacia expresiones más recientes en valores, como los matrimonios de parejas de homosexuales, parejas living apart together, desarrollo de 'nuevas religiones'-, es decir, con valores cercanos a la nueva cultura política (Clark, Hoffmann-Martinot, \& Gromala, 1998; Carreira \& Ramírez, 2008). Las ciudades de Nueva York, Londres, París y Tokio estarían entre las primeras en el ranking de ciudades globales, pero también Los Ángeles, Chicago, Bruselas o Madrid, ocupando esta última el número 17 en el ranking en el año 2010 (A.T. Kearney, 2010).

A continuación se presenta una breve exposición de las condiciones de la ciudad, de distribución espacial de los núcleos urbanos, y de distribución de la población del área metropolitana de Sevilla. Este mapa,

88 Padrón Municipal de Habitantes, Instituto Estadística y Cartografía de Andalucía, año 2015 http://www.juntadeandalucia.es/institutodeestadisticaycartografia 
emulando la idea de Lamo de Espinosa, nos permite anclar el espacio con la tendencia, y tratar de realizar un esbozo de la forma en que se consolida la MCA en el área metropolitana, a partir del estudio de su distribución por barrios y por poblaciones. Así, para Taylor (Taylor, 2001; Taylor et al., 2009) y el thin tank sobre redes urbanas globales de la Universidad de Londres (Globalization and World City-GaWC). Sevilla se situaría entre las ciudades globales altamente suficientes, poseyendo una red de servicios que la hace independiente de los servicios de otras ciudades. Es más, para el año 2012, la ciudad de Sevilla pasaba a la categoría “Gamma” de ciudades globales, ciudades enclave entre la economía global y la región o zona de pertenencia. Claro que no podemos comparar el área metropolitana de Sevilla a la Great London, con cerca de 8,5 millones de habitantes, o a los cerca de 9 millones de personas que habitan la ciudad de México, o a los 14 millones de Nueva Delhi. Las pretensiones de esta ciudad como espacio donde se desarrollan transacciones financieras de las multinacionales y con una densa concentración de expresiones artísticas, son menos ambiciosas. No obstante, Sevilla posee algunas ventajas que la hacen un lugar privilegiado de visita y de habitabilidad. Pese al 1.500.000 de habitantes de su área metropolitana, y a un crecimiento suburbano difuso (Coq, 2012), es una ciudad que se puede pasear, y está llena de espacios que invitan al ocio y al esparcimiento (Garcia et al., 2007). La zona del casco antiguo ha visto florecer, unos años para atrás, espacios antes abandonados. Muchos de los tradicionales corralones, antiguas casas vecinales distribuidas alrededor de un patio, o corral, se han recuperado, ocupándose por arquitectos, diseñadores, escultores, pintores, con actuaciones en vivo de flamenco, jazz, indi..., y oferta de bares. La zona de San Julián ha visto florecer de forma especial estas estructuras en forma de corrala, y una actividad cultural y artística se ha desarrollado alrededor de la misma, conociéndose por la zona del “el soho sevillano”. La zona cercana a la plaza de La Encarnación, conocida familiarmente como 'las setas', por la estructura arquitectónica erigida y que recuerda a ese vegetal, ha visto florecer una zona comercial y de restauración en los últimos años, con un estilo en su oferta de servicios que le ha dado el sobrenombre del "camden sevillano”.

Por otro lado, las desigualdades sociales son menos acentuadas que en otras ciudades con una mayor densidad poblacional. Frente a las tesis sostenidas por Sassen (1994) sobre el aumento de la desigualdad en las ciudades globales, con una mayor localización de las poblaciones con menos recursos en la periferia de la metrópoli, Sevilla no parece haber seguido este patrón. Las poblaciones que forman parte del área metropolitana se ordenan en la distribución del territorio, como espacios dormitorio, o como poblaciones que han visto acercarse la capital gracias a la mejora de las comunicaciones y a la llegada de un sector servicios acompañando a la 
población nueva. Las zonas con mayor riesgo de pobreza y exclusión social siguen siendo los tradicionales espacios, localizados principalmente en la zona de las 'tres mil vivienda', en el distrito sur, y la zona de 'El bacie' en el distrito norte.

Imagen 1. Distribución de la población en Sevilla y primera corona área metropolitana ${ }^{89}$.

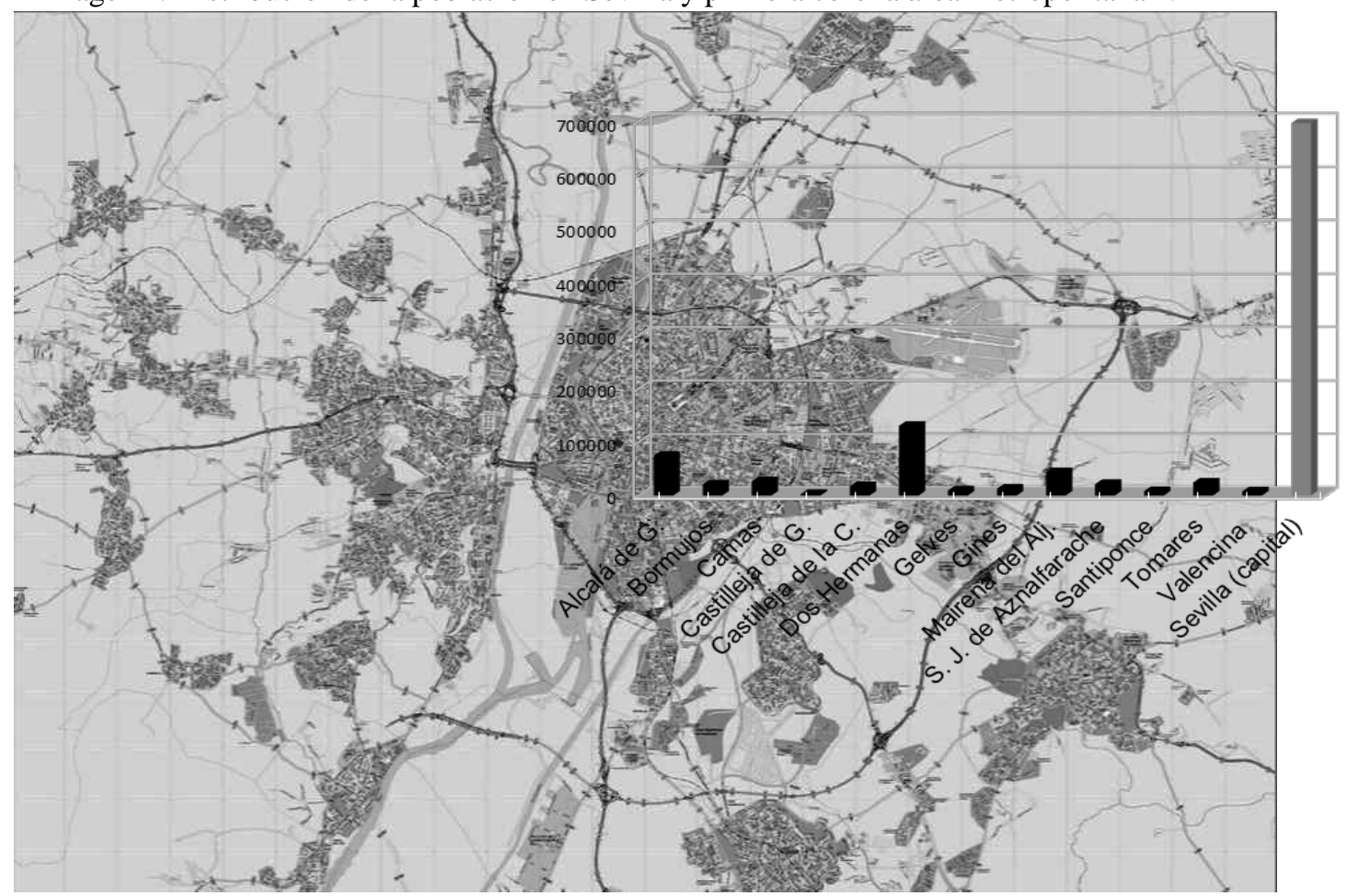

Fuente: IECA, Padrón Municipal 2016, y elaboración propia.

La imagen 1 muestra el mapa del área metropolitana de Sevilla, junto a la distribución de la población de la capital y los municipios de la primera corona metropolitana. Sevilla tiene la particularidad de poseer dos ramificaciones del río Guadalquivir, que la atraviesan de norte a sur. Un brazo del río recorre la capital, y termina en la zona norte de la ciudad. Este brazo se ha conservado a partir del antiguo cauce del río, que a mediados del siglo XX se modificó, en parte para paliar las inundaciones a las que la ciudad era sometida con las subidas del río (Mena, 2003; Moral, 1996). Otra ramificación, el cauce propiamente del río Guadalquivir en la actualidad, está situada al oeste de la ciudad, y es conectada con esta y con los municipios de esa zona, mediante los puentes como el de El Quinto Centenario o el de El Alamillo. Estos puentes sirve de conexión diaria de las poblaciones de la zona oeste, como Camas o Tomares, y de la zona norte, como Santiponce, y

89 La imagen de la ciudad de Sevilla se ha localizado en http://www.mapasmurales.es/mapa-sevilla/. 
que conecta con la autovía norte, conocida como Ruta de la Plata. En la zona al sur, sur-este, de la capital, encontramos poblaciones como Dos Hermanas y Alcalá de Guadaira, que, aunque pertenecen a la segunda corona metropolitana, son núcleos de población importantes, haciendo una labor de ciudad dormitorio de forma particular.

En su conjunto, se observa que la ciudad de Sevilla concentra la mayor población, con alrededor de 700.000 habitantes, siendo el resto de poblaciones habitadas por menos de 25.000 habitantes, a excepción, como se ha señalado, de Dos Hermanas, que supera los 100.000 habitantes, y Alcalá de Guadaira, con cerca de 75.000, ambas en la zona sur. A ellas se acerca Mairena del Aljarafe, en la zona oeste de Sevilla, con una población que ronda los 50.000 habitantes. De hecho, la zona del Aljarafe se constituye como un entramado de municipios conectados entre sí y con su propia dinámica: Mairena, Bormujos, Tomares, San Juan de Aznalfarache, por un lado, Gines y Castilleja de la Cuesta, por otro lado, separados por la autovía que lleva a las playas de Huelva.

En el siguiente apartado tratamos de responder a las preguntas ¿cómo se distribuye la oferta de estas actividades a nivel espacial? Los centros y profesionales se reparten por igual entre los barrios de la ciudad, y entre estos y las zonas del área metropolitana, o este reparto es desigual? Y si fuera este último el caso, ¿hay algún patrón que explique la desigual distribución?

\section{Tendencias en la Ciudad de Sevilla}

En primer lugar, se muestra la presencia de esta tendencia en la ciudad de Sevilla, para en un segundo momento compararla con las poblaciones comprendidas en el área metropolitana. Para el análisis se ha tenido en cuenta como criterio de distribución espacial el distrito, al establecer un mapa del territorio bastante conocido y accesible. Para el área metropolitana, el análisis se realiza sobre la ciudad de Sevilla y los municipios de la primera corona metropolitana. En el Anexo 4 y en el Anexo 5 pueden localizarse los municipios comprendidos en las coronas metropolitanas y su distribución espacial. Se ha seleccionado sólo las poblaciones de la primera corona metropolitana por la cercanía que suponen a la capital, y su constante flujo de población de la capital a los pueblos, y viceversa. Los municipios de la segunda, tercera, cuarta y quinta corona, pese a tener una red de contactos importantes, no participan, no obstante, de esta densidad de interacción. Las excepciones hechas son los municipios de Alcalá de Guadaira y Dos Hermanas, pues como se ha comentado más arriba, son ciudades con un flujo diario de población hacia la capital. Para el análisis se ha considerado a todos los municipios de la primera corona metropolitana como integrantes de un distrito. Aunque el distrito no es la 
mejor herramienta sociológica para poder hacer interpretaciones de la realidad sevillana, ya que en un distrito pueden verse aglutinados diferentes estratos sociales, este texto irá haciendo precisiones y matizaciones que oportunamente, creemos, conducirán al lector a una comprensión de la distribución espacial de la ciudadanía sevillana por clase social y acceso a los recursos.

Por ejemplo, el distrito Sevilla Este-Alcosa-Torreblanca contiene poblaciones tanto con escaso acceso a los recursos, y condiciones materiales de existencia básicamente cubiertas, como estratos de población acomodados, profesionales liberales y empleados por cuenta ajena cualificados. El distrito La Palmera-Bellavista comprende uno de los barrios más lujosos de Sevilla, con bellas edificaciones y casas señoriales, fruto de la expansión que vivió la ciudad en la Exposición Iberoamericana de 1929. Ese mismo distrito comprende una zona que en la actualidad habita una población inmigrante de origen económico. El distrito Sur, a su vez, comprende zonas como el Parque de María Luisa, con una afluencia diaria de turismo nacional e internacional, espacios con fuerte desarraigo y desestructuración familiar, como el barrio Las Tres Mil Viviendas, y familias de clase obrera no cualificada.

La imagen 2 presenta los porcentajes de espacios y profesionales de medicina complementaria y alternativa según distritos ${ }^{90}$. Suponen un total del $73 \%$ de la oferta, frente al $27 \%$ que se aglutina en los municipios de la primera corona metropolitana. La imagen 2 muestra una fuerte diferenciación espacial en la oferta de estas prácticas, con diferencias de hasta 10 puntos porcentuales entre unos distritos y otros. Y serían los situados en la zona centro de la ciudad los que marcan la tendencia: de 11 distritos, serían 3, Casco Antiguo, Macarena y Nervión el espacio urbano que concentra la oferta, con cerca de un 44\%. El centro de la metrópoli parece, pues, que marca las tendencias en MCA. Espacio que, como se ha señalado más arriba, no sólo expresa la tendencia en esta manifestación en salud y bienestar personal, sino que se ha erigido como territorio vanguardista de la ciudad sevillana. Estos tres distritos concentran, además, una población de clase social media, media-alta, con incorporación de nuevas clases medias, profesionales liberales como abogados, arquitectos, diseñadores, funcionarios de la administración del gobierno regional, además de empresarios, freelances y autónomos. No obstante, la zona más al norte del distrito Macarena, y la zona más al este del distrito Nervión, rompen con la homogeneidad de la clase social: son zonas con población inmigrante de

\footnotetext{
${ }^{90}$ La imagen es adaptada de la expuesta en la página web del ayuntamiento de Sevilla, http://www.sevilla.org/urbanismo/.
} 
origen económico, y clases medias o clases bajas con profesiones no cualificadas.

Imagen 2. Porcentaje de espacios de medicina complementaria y alternativa por distrito.

Ciudad de Sevilla.

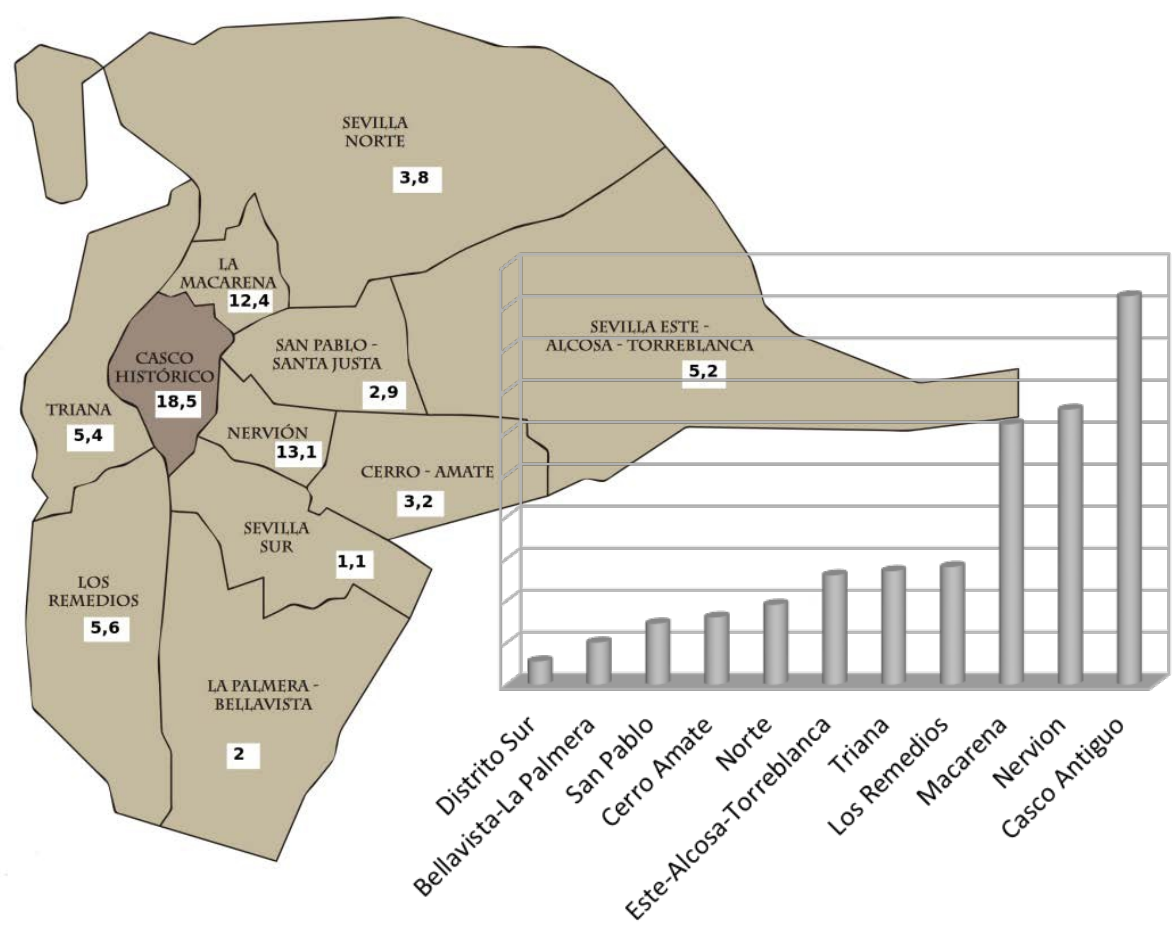

Fuente: Elaboración propia, 2016

A este grupo de distritos le siguen, en menor medida, tres distritos con unos barrios con un surgimiento muy desigual. El tradicional barrio de Triana, con su idiosincrasia y particularidad propias, en parte acentuado por ese legado de estar "al otro margen" del río" ${ }^{91}$ Los Remedios, habitado por una clase media funcionarial que se instala en la zona a finales de la década de los 60, y durante los 70; y Sevilla Este, barrio de nueva creación que se ha convertido en un espacio con un conjunto de ofertas de actividades y servicios tan variado que ha generado su propia dinámica social. En su conjunto, representa alrededor del $16 \%$ de la oferta de este tipo de actividades. El 13 \% restante se localiza en cinco distritos: La PalmeraBellavista, Distrito Sur, Cerro-Amate, San Pablo-Santa Justa y Distrito Norte, los barrios más periféricos situados en el margen derecha del río

91 Triana y Sevilla como dos espacios de hábitat enfrentados simbólicamente, cuya máxima expresión es 'soy de Triana' en clara alusión a que no se es de Sevilla, se es de Sevilla y Triana. 
Guadalquivir. Por tanto, la oferta de MCA se distribuye espacialmente en el casco urbano sevillano con una densidad en el centro que va dispersándose conforme se aleja del mismo.

\section{Tendencias en el Área Metropolitana de Sevilla}

El 27\% restante de la oferta, como se ha referido, se distribuye entre las poblaciones del área metropolitana, en concreto en la primera corona metropolitana, más los municipios de Dos Hermanas y Alcalá de Guadaira. Como Mairena del Aljarafe, o Gines, Alcalá de Guadaira y Dos Hermanas son municipios desde los que diariamente se producen desplazamientos a la capital, principalmente por cuestiones de tipo laboral, y se regresa para hacer la vida en el hogar. La imagen 3 muestra, por un lado, los municipios de la corona metropolitana, y su distribución alrededor de la ciudad de Sevilla. Por otro lado, una gráfica comparativa de Sevilla-Municipios Primera Corona Metropolitana, con la oferta de actividades de MCA, y la población que habita en uno y otro espacio. En concreto, la imagen 3 presenta los resultados de la distribución de frecuencias de la oferta de la medicina alternativa en Sevilla comparada con la primera corona del área metropolitana. En ella puede observarse que alrededor de un $73 \%$ de la oferta se localiza en la capital, frente al 27\% localizado en el área metropolitana. El segundo grupo de columnas muestra, en cambio, los resultados de la distribución de frecuencias de la población viviendo en un espacio y el otro, según los datos del padrón municipal del año 2014. En ella se observa que cerca de un $40 \%$ de la población vive fuera de la capital, frente a algo más del 60\% que vive en ella.

Esta información permite afirmar que los servicios de MCA presentes en el área metropolitana parecen no corresponder con la población que vive en la misma. La concentración de servicios de MCA sigue localizándose en la capital, pese a que un peso importante de población vive en la corona metropolitana. Ello podría estar indicando que la oferta de medicina complementaria y alternativa en el área metropolitana no cubre toda la posible demanda. De hecho, la proporción de centros de medicina complementaria y alternativa por persona, en Sevilla y en esta primera corona metropolitana, expresa empíricamente esta idea: la proporción es casi el doble en Sevilla que en la primera corona, esto es, una persona viviendo en la ciudad de Sevilla tiene el doble de ofertas de servicios en MCA que una persona viviendo en la primera corona metropolitana ${ }^{92}$. 
Imagen 3. Oferta de medicina complementaria y alternativa y población. Ciudad de Sevilla y primera corona área metropolitana. Porcentajes.

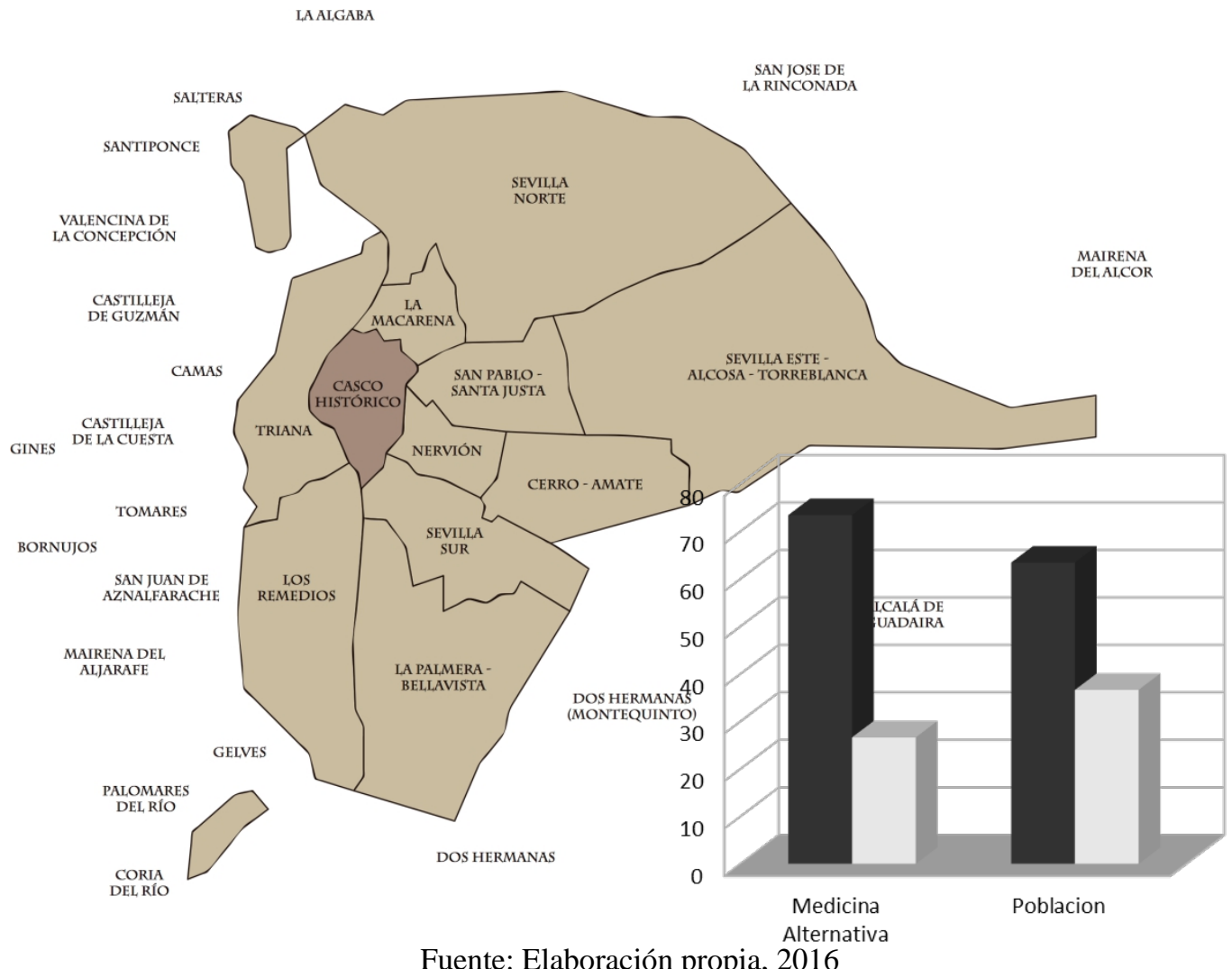

- Ciudad Sevilla $\square$ Area Metropolit

Consolidación, por tanto, de la oferta, en la zona centro del área metropolitana principalmente, perdiendo fuerza conforme se aleja de esta zona, e incluso sin llegar a consolidarse en el área metropolitana, pese a existir municipios y zonas dentro del área, con un gran dinamismo comercial y de servicios. Parece que existiría, pues, una distribución desigual de la oferta de estas actividades. Faltaría saber, no obstante, si la misma se debe a la recuperación del casco antiguo, zona habitada por la vanguardia empresarial y artística, y por tanto, concentración de nuevas tendencias, o se debe, en cambio, a que, pese que hay demanda de estas actividades en otras zonas de la ciudad, el territorio constriñe el riesgo de la iniciativa empresarial a la zona "segura”. De hecho, y aunque no es objeto de este estudio, la segunda parece ser el presupuesto más plausible, pues el distrito Sur, como ya se sabe, de los más humildes, es el que concentra en espacios públicos un mayor número de actividades de medicina complementaria y alternativa. Es decir, aquí la demanda parece haberse llenado con ofertas de iniciativa municipal. 


\section{Conclusion}

En estas páginas se ha tratado de presentar un mapa de la ciudad sevillana del siglo XXI. Para ello, frente a las visiones tradicionales de Sevilla como el referente de actividades de ocio y esparcimiento como la Feria de Abril o la Semana Santa, el documento trata de mostrar una Sevilla desde una nueva óptica o visión, de lo que también es la ciudad y la ciudadanía que la integra. Ello se ha presentado a partir de dos realidades sociales diferentes. Por un lado, la emergencia de una tendencia innovadora, la MCA, que podría estar iniciando cambios en la concepción del cuidado o de la atención a la salud entre la población (Ramírez, 2016). Y por otro lado, situar la ciudad de Sevilla entre aquellas ciudades que forman parte de la red de ciudades globales a nivel mundial. En el primer caso, nos encontramos una ciudad que ha incorporado nuevas prácticas asociadas a la salud y el bienestar, y que trata de complementar o integrar con las convencionales formas de salud presentes en la sociedad española en general y sevillana en particular. Ejemplo de ello son los cerca de 450 centros y profesionales presentes tanto en la ciudad como en el área metropolitana, donde se desarrollan una miríada de actividades, o lo que ha venido a conocerse como "el mercadillo de las terapias”, en clara alusión a la gran variedad presente esta ciudad. En el segundo caso, observamos que Sevilla forma parte de la red de ciudades globales, como conectora de la economía regional a la economía global. De hecho, situarla en la clasificación del ranking GaWC como ciudad tipo $C$ por su importancia en el entramado global, parece indicar su participación en el capital financiero, humano y cultural en la red económica global. Parece ser, pues, que Sevilla, a diferencia del resto de ciudades del sur de España, se presenta como portadora de nuevas tendencias en el entramado de redes de ciudades globales.

Este mapa de las tendencias en esta ciudad sevillana hace reflexionar sobre una situación paradójica en la era de la modernidad en transformación, o modernidad tardía. Paradoja expresada, por un lado, en la búsqueda de alternativas al espacio vital del ser humano, como es la salud, alternativas que se basan en principios axiológicos holísticos e integradores, y que quizás expresen cambios culturales con el devenir del tiempo. Y por otro lado, esta moda en salud se expresa en ciudades con dinámicas asociadas a las lógicas del sistema económico capitalista, una lógica principalmente instrumental y asociada a la obtención de un beneficio material y económico. Podríamos decir que ambos elementos analizados aquí se alimentan de los conceptos de bienestar subjetivo y bienestar objetivo (Hamilton, 2006), y que expresarían, quizás, con Edgar Morín (2010), ese pensamiento complejo que está presente en las sociedades contemporáneas. 


\section{References:}

1. A.T. Kearney (2010). The urban elite. The A. T. kearny global cities index 2010. Chicago: A. T. Kearney, Inc.

2. Ayuntamiento de Sevilla (2005). Plan general de ordenación urbana. Sevilla: Ayuntamiento de Sevilla.

3. Bartolini, S. (1986). Metodología de la investigación política. In G. e. a. Pasquino (Ed.), Manual de ciencia política (pp. 39): Madrid: Alianza.

4. Bauman, Z. (2009). El arte de la vida. de la vida como obra de arte. Barcelona: Paidós.

5. Beaverstock, J. V., Smith, R. G., \& Taylor, P. J. (2000). World-city network: A new metageography? Annals of the Association of American Geographers [H.W.Wilson - SSA], 90(1), 123. Retrieved

6. Boudon, R. (1981). La lógica de lo social: Introducción al análisis sociológico. Madrid: Rialp.

7. Capra, F. (1984). El tao de la física: Una exploración de los paralelos entre la física moderna y el misticismo oriental (1st ed.) Madrid: Luis Cárcamo, D.L. 1984.

8. Carreira F, Ramirez A. (2008). Clase, cidade e poder. Cidade e cidadania. Governaça urbana e participaçao cidada. Lisboa: Impresa de Ciencias Sociais.

9. Clark, T. N., Hoffmann-Martinot, V., and Gromala, M. (1998). The new political culture. Colorado: West View Press.

10. Coq, D. (2012). Crecimiento suburbano difuso y sin fin en el área metropolitana de sevilla entre 1980 y 2010. algunos elementos explicativos. Scripta Nova, XVI (397), 1-31.

11. Elster, J. (2003). Tuercas y tornillos: Una introducción a los conceptos básicos de las ciencias sociales (3a reimp. ed.). Barcelona: Gedisa.

12. Erner, G. (2013). Sociologia de las tendencias. Barcelona: Gustavo Gili.

13. Foucault, M. (1979). Microfísica del poder (Segunda ed.). Madrid: Las Ediciones de La Piqueta.

14. Garcia, et al. (2007). Paisajes simbólicos de la ciudad de Sevilla. Ería, (73-74), 291-310.

15. Hamilton, C. (2006). El fetiche del crecimiento. Pamplona: Laetoli.

16. Lamo de Espinosa, E. (2005). ¿Para qué la ciencia social? ¿Para quién escribimos? Nómadas, 11(1), 1-12.

17. Ministerio de Sanidad (2011). Análisis de la situación de las terapias naturales. Madrid: Ministerio de Sanidad, Política Social e Igualdad.

18. Morin, E. (2010). ¿Hacia el abismo? globalización en el siglo XXI. Barcelona: Paidos Iberica. 
19. Observatorio Terapias Naturales (2008). Presentación del primer estudio sobre uso y hábitos de consumo de las terapias naturales en españa. Madrid: Observatorio Terapias Naturales.

20. Ramírez, A. and Márquez, M.A. (2017). Las asociaciones de salud y bienestar personal en Andalucía: Oportunidades, motivaciones y anclajes. En: Políticas públicas y organizaciones de la sociedad civil. México y España. México D.F.: UNAM (En prensa).

21. Ramírez, A. (2017). Complementary and alternative medicine as a functional tendency. Formation of preferences, agency, and diffusion among citizenships. European Scientific Journal, 2016; 12(26), 5272.

22. Sassen, S. (1991). The global city: New york, london, tokyo (2nd ed.). Princeton: Princeton University Press.

23. Sassen, S. (1994). Cities in a world economy. New York: Pine Forge Press.

24. Sproles, G. B. (1974). Fashion theory: A conceptual framework. Advances in Consumer Research, 01, 463-472.

25. Taylor, P. J. (2001). Specification of the world city network. Geographical Analysis, 33(2), 181-194.

26. Taylor, et al. (2009). Measuring the world city network: New results and developments. GaWC Research Bulletin, 300

Nota: Agradecimientos a los Alumnos Internos de la Promoción 2013-14, y en especial a Raúl Navarro.

\section{ANEXO 1. METODOLOGIA GENERAL PARA ELABORACIÓN DE LA BASE DE DATOS}

La recogida de la información se realiza durante los años 2013-2014. La recogida se hace a
través de la herramienta Internet, principalmente, localizando la información en base a dos
coordenadas fundamentales: distrito y actividad. El distrito permite que se rastree toda la
zona geográfica seleccionada, y se vaya haciendo un seguimiento de las zonas rastreadas y
las que quedan por rastrear. Permite, a su vez, detectar posibles errores en la recogida de la
información, pues las posibles ausencias de actividad en alguna zona puede visualizarse, o
consultar si es un error de recogida de información, o forma parte de la realidad observada.
Para realizar la recogida a partir de los distritos, se localizan los códigos postales
municipales y se van asignando las zonas postales a los distritos correspondientes. Cuando
un código postal se localiza en dos distritos, se ha optado por incluirlo en el distrito en el que
mayormente forma parte.
La actividad se refiere a la localización de las actividades en medicina complementaria y
alternativa existentes en la zona geográfica seleccionada. La búsqueda se ha realizado en
forma abanico: de una información inicial existente se ha ido abriendo el abanico de
información. Esta información inicial se refiere tanto al tipo de actividad como a espacios 
donde se desarrolla. Además permite localizar tipos de actividad similares en otras barriadas, y centros donde se desarrollaban esas actividades, pero también actividades que aún no se habían incluido en la base de datos. Junto a esta forma de proceder, la localización de la actividad también se ha realizado a partir de la inclusión de palabras clave en el buscador de Internet.

Las variables incluidas en la base de datos son las que aparecen listadas más abajo, además del listado de actividades mostrado en otro de los Anexos.

Listado variables

1. Tipo: tipo de espacio donde se desarrolla la actividad--- categorías: 1'Asociacion' 2

'Centro' 3 'Consulta' 4 'A domicilio' 5 'Herbolario' 6 'Otros, cuál'.

2. Nombre de la asociación, centro, la persona --- categorías: es una variable de cadena, aparece el nombre exacto. Por ejemplo, si se desarrolla en un centro, el nombre del centro, si se desarrolla por una persona, el nombre de la persona.

3. Persona---- categorías: 1'Persona física' 2'Persona jurídica'

4. Personalidad--- categorías 1'Personalidad Publica' 2'Personalidad privada'

5. Distrito --- es la división territorial del espacio en las ciudades en España --- categorías

1'Macarena' 2 'Norte' 3 'Bellavista-La Palmera' 4 'Distrito Sur' 5 'Triana' 6 'Casco

Antiguo' 7 'Nervion' 8 'San Pablo' 9 'Alcosa' 10 'Cerro Amate' 11 'Torreblanca' 12 'Area

Metropolitana'.

6. Direccion--- categoría: es una variable de cadena 'Dirección postal'

7. Email --- categoría: es una variable de cadena 'Dirección e-mail'

8. Telefono--- categoría: número de 'Teléfono'

9. Web--- categoría: es una variable de cadena 'Página Web'

10. Coment --- categoría: es una variable de cadena, se escriben los precisiones necesarias y que no puedan contenerse en las otras variables.

También se ha solicitado la información estadística al Instituto de Estadística y Cartografía de Andalucía (IECA). No obstante, la clasificación Nacional de Actividades Económicas (CNAE) 2009 en que se basa para recoger los datos, no contempla la recogida de este tipo de actividades. Lo más cercano que existe es el Código de establecimientos sanitarios 'otros establecimientos' donde se incluyen centros de psicodrama, laboratorios farmacéuticos, oftalmología u otros centros no clasificados en otros códigos de actividades sanitarias de la CNAE.

ANEXO 2. LISTADO DE ACTIVIDADES. DESCRIPTIVOS; Años 20132014.

\begin{tabular}{|c|c|c|c|c|}
\hline & & \multicolumn{2}{|c|}{ Respuestas } & \multirow{2}{*}{$\begin{array}{c}\begin{array}{c}\text { Porcentaje de } \\
\text { casos }\end{array} \\
\mathrm{N}^{\mathrm{o}}\end{array}$} \\
\hline & & $\mathrm{N}^{\mathrm{o}}$ & Porcentaje & \\
\hline \multirow[t]{8}{*}{ Actividades } & Acupuntura, MTChina & 77 & $5,8 \%$ & $18,5 \%$ \\
\hline & Analisis Bioenergético & 14 & $1,0 \%$ & $3,4 \%$ \\
\hline & Apiterapia & 1 &, $1 \%$ &, $2 \%$ \\
\hline & Aromaterapia & 21 & $1,6 \%$ & $5,0 \%$ \\
\hline & Arteterapia & 5 & ,4\% & $1,2 \%$ \\
\hline & Asistencia Maternidad, Doula & 2 & , $1 \%$ &, $5 \%$ \\
\hline & Auriculoterapia, auriculopuntura & 29 & $2,2 \%$ & $7,0 \%$ \\
\hline & Baunscheidt (Terapia ventosas) & 1 &, $1 \%$ &, $2 \%$ \\
\hline
\end{tabular}




\begin{tabular}{|c|c|c|c|}
\hline Biodanza & 4 &, $3 \%$ & $1,0 \%$ \\
\hline Biorresonancia & 3 &, $2 \%$ & ,7\% \\
\hline Coaching & 3 &, $2 \%$ &, $7 \%$ \\
\hline Constelaciones Familiares & 1 &, $1 \%$ &, $2 \%$ \\
\hline Cromoterapia & 7 &, $5 \%$ & $1,7 \%$ \\
\hline Cupping, MTChina & 3 &, $2 \%$ & ,7\% \\
\hline Danzaterapia & 2 &, $1 \%$ &, $5 \%$ \\
\hline Dietoterapia & 7 &, $5 \%$ & $1,7 \%$ \\
\hline Digitopuntura & 18 & $1,3 \%$ & $4,3 \%$ \\
\hline Drenaje Linfático & 38 & $2,8 \%$ & $9,1 \%$ \\
\hline Electroacunpuntura & 4 &, $3 \%$ & $1,0 \%$ \\
\hline EMFBalancing, Armonización energética & 1 &, $1 \%$ &, $2 \%$ \\
\hline Estimulacion Precoz,infancia & 12 &, $9 \%$ & $2,9 \%$ \\
\hline Fangoterapia & 13 & $1,0 \%$ & $3,1 \%$ \\
\hline Fitoterapia & 20 & $1,5 \%$ & $4,8 \%$ \\
\hline Flores Alba & 6 &, $4 \%$ & $1,4 \%$ \\
\hline Flores Bach & 47 & $3,5 \%$ & $11,3 \%$ \\
\hline Flores California & 3 &, $2 \%$ &, $7 \%$ \\
\hline Gemoterapia & 7 &, $5 \%$ & $1,7 \%$ \\
\hline Gestalt & 15 & $1,1 \%$ & $3,6 \%$ \\
\hline Hidroterapia & 6 &, $4 \%$ & $1,4 \%$ \\
\hline Hipnoterapia, Hipnosis Ericksoniana & 21 & $1,6 \%$ & $5,0 \%$ \\
\hline Iridologia & 3 & ,2\% &, $7 \%$ \\
\hline Kinesiologia & 34 & $2,5 \%$ & $8,2 \%$ \\
\hline Logoterapia & 3 & ,2\% &, $7 \%$ \\
\hline Macrobiotica & 1 & ,1\% &, $2 \%$ \\
\hline Magnetoterapia & 9 & ,7\% & $2,2 \%$ \\
\hline Masaje Californiano & 8 & ,6\% & $1,9 \%$ \\
\hline Masaje Circulatorio & 9 & ,7\% & $2,2 \%$ \\
\hline Masaje Con Piedras Calientes & 11 & ,8\% & $2,6 \%$ \\
\hline Masaje Miofascial & 14 & $1,0 \%$ & $3,4 \%$ \\
\hline Masaje Sueco & 6 &, $4 \%$ & $1,4 \%$ \\
\hline Masaje Tailandés & 6 &, $4 \%$ & $1,4 \%$ \\
\hline Masaje Transverso Profundo & 9 & ,7\% & $2,2 \%$ \\
\hline MasajeBalinés & 4 & ,3\% & $1,0 \%$ \\
\hline Medicina Ayurveda & 13 & $1,0 \%$ & $3,1 \%$ \\
\hline Medicina Homeopatica & 47 & $3,5 \%$ & $11,3 \%$ \\
\hline Medicina Ortomolecular & 5 &, $4 \%$ & $1,2 \%$ \\
\hline Medicina Tradicional China, MTChina & 18 & $1,3 \%$ & $4,3 \%$ \\
\hline
\end{tabular}




\begin{tabular}{|c|c|c|c|}
\hline Meditacion & 36 & $2,7 \%$ & $8,7 \%$ \\
\hline Mesoterapia & 16 & $1,2 \%$ & $3,8 \%$ \\
\hline Metamedicina & 3 &, $2 \%$ & ,7\% \\
\hline Moxibustion, MTChina & 13 & $1,0 \%$ & $3,1 \%$ \\
\hline Musicoterapia & 11 &, $8 \%$ & $2,6 \%$ \\
\hline Naturopatia & 40 & $3,0 \%$ & $9,6 \%$ \\
\hline Nueva Medicina Germanica, NMG & 1 &, $1 \%$ &, $2 \%$ \\
\hline Oligoterapia & 16 & $1,2 \%$ & $3,8 \%$ \\
\hline Osteopatia & 35 & $2,6 \%$ & $8,4 \%$ \\
\hline Ozonoterapia & 1 &, $1 \%$ &, $2 \%$ \\
\hline Par Biomagnetico & 11 &, $8 \%$ & $2,6 \%$ \\
\hline Pilates & 60 & $4,5 \%$ & $14,4 \%$ \\
\hline Psicodrama & 13 & $1,0 \%$ & $3,1 \%$ \\
\hline PsychK & 2 &, $1 \%$ &, $5 \%$ \\
\hline QuiGong & 14 & $1,0 \%$ & $3,4 \%$ \\
\hline Quiromasaje & 52 & $3,9 \%$ & $12,5 \%$ \\
\hline Quiropráctica & 15 & $1,1 \%$ & $3,6 \%$ \\
\hline Rebirthing, Renacimiento & 1 & ,1\% &, $2 \%$ \\
\hline Reeducación Postura Global, Fisioterapia & 19 & $1,4 \%$ & $4,6 \%$ \\
\hline Reflexokinesia & 2 & , 1\% &, $5 \%$ \\
\hline Reflexologia & 46 & $3,4 \%$ & $11,1 \%$ \\
\hline Reiki & 55 & $4,1 \%$ & $13,2 \%$ \\
\hline Respiración Holotrópica & 1 &, $1 \%$ &, $2 \%$ \\
\hline Risoterapia & 8 &, $6 \%$ & $1,9 \%$ \\
\hline Rolfing, Reestrucutracion Fascial & 2 &, $1 \%$ &, $5 \%$ \\
\hline Sanación Reconectiva & 1 &, $1 \%$ &, $2 \%$ \\
\hline Sanción Cuántica & 1 &, $1 \%$ &, $2 \%$ \\
\hline Shiatsu & 25 & $1,9 \%$ & $6,0 \%$ \\
\hline Sintergetica & 1 & , 1\% &, $2 \%$ \\
\hline Sofrologia & 2 & ,1\% &, $5 \%$ \\
\hline TaiChi & 30 & $2,2 \%$ & $7,2 \%$ \\
\hline Talasoterapia & 2 & ,1\% &, $5 \%$ \\
\hline Tecnica Metamorfica & 10 & ,7\% & $2,4 \%$ \\
\hline Tecnicas De Relajacion & 20 & $1,5 \%$ & $4,8 \%$ \\
\hline Terapia Con Animales & 3 &, $2 \%$ & ,7\% \\
\hline Terapia Craneosacral & 25 & $1,9 \%$ & $6,0 \%$ \\
\hline Terapia De Pareja, Sexual & 31 & $2,3 \%$ & $7,5 \%$ \\
\hline Terapia De Polaridad & 2 & ,1\% &, $5 \%$ \\
\hline Terapia EMDR & 2 &, $1 \%$ &, $5 \%$ \\
\hline
\end{tabular}




\begin{tabular}{|c|c|c|c|c|}
\hline & Terapia Neural & 1 &, $1 \%$ &, $2 \%$ \\
\hline & Terapia Regresiva, Anatheoresis & 6 & ,4\% & $1,4 \%$ \\
\hline & $\begin{array}{c}\text { Terapia Sacrocraneal, Liberacion Somato } \\
\text { Emocional }\end{array}$ & 4 & ,3\% & $1,0 \%$ \\
\hline & Trabajo con Chakras & 22 & $1,6 \%$ & $5,3 \%$ \\
\hline & TuiNa, MTChina & 6 & ,4\% & $1,4 \%$ \\
\hline & Ventosas, MTChina & 6 & ,4\% & $1,4 \%$ \\
\hline & Wing Chun (Kung Fu) & 1 & ,1\% &, $2 \%$ \\
\hline & Yoga & 73 & $5,5 \%$ & $17,5 \%$ \\
\hline Total & & 1338 & $100,0 \%$ & $321,6 \%$ \\
\hline
\end{tabular}

\section{ANEXO 3. ACTIVIDADES INCLUIDAS EN CADA UNA DE LAS CATEGORÍAS CLASIFICATORIAS}

En la clasificación, se incluyen las siguientes actividades y prácticas en cada una de las categorías creadas:

1. Sistemas integrales Acupuntura, MTChina. Consultoria Chamanica. Cupping, MTChina. o completos Medicina Ayurveda. Medicina Homeopatica. Medicina Tradicional China, MTChina. Moxibustion, MTChina. Naturopatia. Nueva Medicina Germanica, NMG. TuiNa, MTChina. Ventosas, MTChina.

2. Técnicas sobre la Biodanza. Danzaterapia.Kinesiologia. Meditacion. Metamedicina. Pilates. base de la conciencia QuiGong (Chi Kung) Respiración Holotrópica. Sofrologia. TaiChi. Tecnicas (mente-cuerpo) De Relajacion. Yoga. Wing Chun (Kung Fu).

3. Prácticas biológicas AguaTerapia, Movimiento Acuatico Reequilibrante, Acuabalance. y con elementos de la Apiterapia. Aromaterapia. Dietoterapia. Fangoterapia. Feng Shui.Flores (de naturaleza Bach, de Alba, de California). Fitoterapia. Gemoterapia. Hidroterapia. Macrobiotica. Medicina Ortomolecular. Oligoterapia. Ozonoterapia. Talasoterapia. Watsu, Agua Terapia. Terapia Con Animales.

4. Prácticas de manipulación y basadas en el cuerpo

Auriculoterapia, auriculopuntura. Baunscheidt (Terapia ventosas). Digitopuntura. Drenaje Linfático. Electroacunpuntura. Iridologia. Masaje.MasajeBalinés. Masaje Californiano. Masaje Circulatorio. Masaje Con Piedras Calientes. Masaje Cyriax. Masaje Infantil. Masaje Miofascial. Masaje Sueco. Masaje Tailandés. Masaje Transverso Profundo. Mesoterapia. Osteopatia. Percutor Estructural. Quiromasaje. Quiropráctica. Reeducación Postura Global. Reflexokinesia. Reflexologia. Rolfing, Reestrucutracion Fascial. Shiatsu.Terapia Sacrocraneal, Liberacion Somato Emocional.Terapia Neural. Terapia Craneosacral. Tecnica Metamorfica.

5. Técnicas sobre la Biorresonancia. Balance Polar Electromagnetico. Cromoterapia. base de la energía EMFBalancing, Armonización energética. Magnetoterapia. Par Biomagnetico. Rebirthing, Renacimiento. Reiki. Sintergetica.Sanergia. Sanación Reconectiva. Sanción Cuántica.Tecnica Reequilibrio Corporal Damun,TRCD. Trabajo con Chakras. Terapia De Polaridad.

6. Técnicas con base en la psique $y$ patrones mentales
Analisis Bioenergético, (Lowen). Arteterapia. Asistencia Maternidad, Doula. Coaching. Constelaciones Familiares. Estimulacion Precoz,infancia. Gestalt. Grafoterapia. Hipnoterapia, Hipnosis Ericksoniana. Inteligencia Emocional. Logoterapia. Musicoterapia. Psicodrama. PsychK. Programacion Neurolinguistica, PNL.Risoterapia. Sinergetica.Terapia EMDR. Terapia Regresiva, Anatheoresis, Terapia De Pareja, Sexual. 


\section{ANEXO 4. CORONAS EN EL AREA METROPOLITANA DE SEVILLA}

El Plan de Ordenación Urbana de 2005 definía el territorio de Sevilla como Área Metropolitana (Ayuntamiento de Sevilla, 2005), e incluía en el mismo las localidades comprendidas. La imagen presenta las coronas metropolitanas clasificadas según el Consorcio de Transporte Metropolitano del Área de Sevilla (CTAS). Para la selección de las coronas y los muncipios se ha atendiudo a la información facilitada por:

-Consorcio de Transporte Metropolitano del Área de Sevilla (CTAS)

http://www.consorciotransportes-sevilla.com/lineasmetropolitanas/lineas/lineas.php

- Instituto de estadística y cartografía de Andalucía (IECA)

http://www.juntadeandalucia.es/institutodeestadisticaycartografia/ieagen/catalogo/cartografi a/descargas/Plano_metrop_Sevilla.pdf

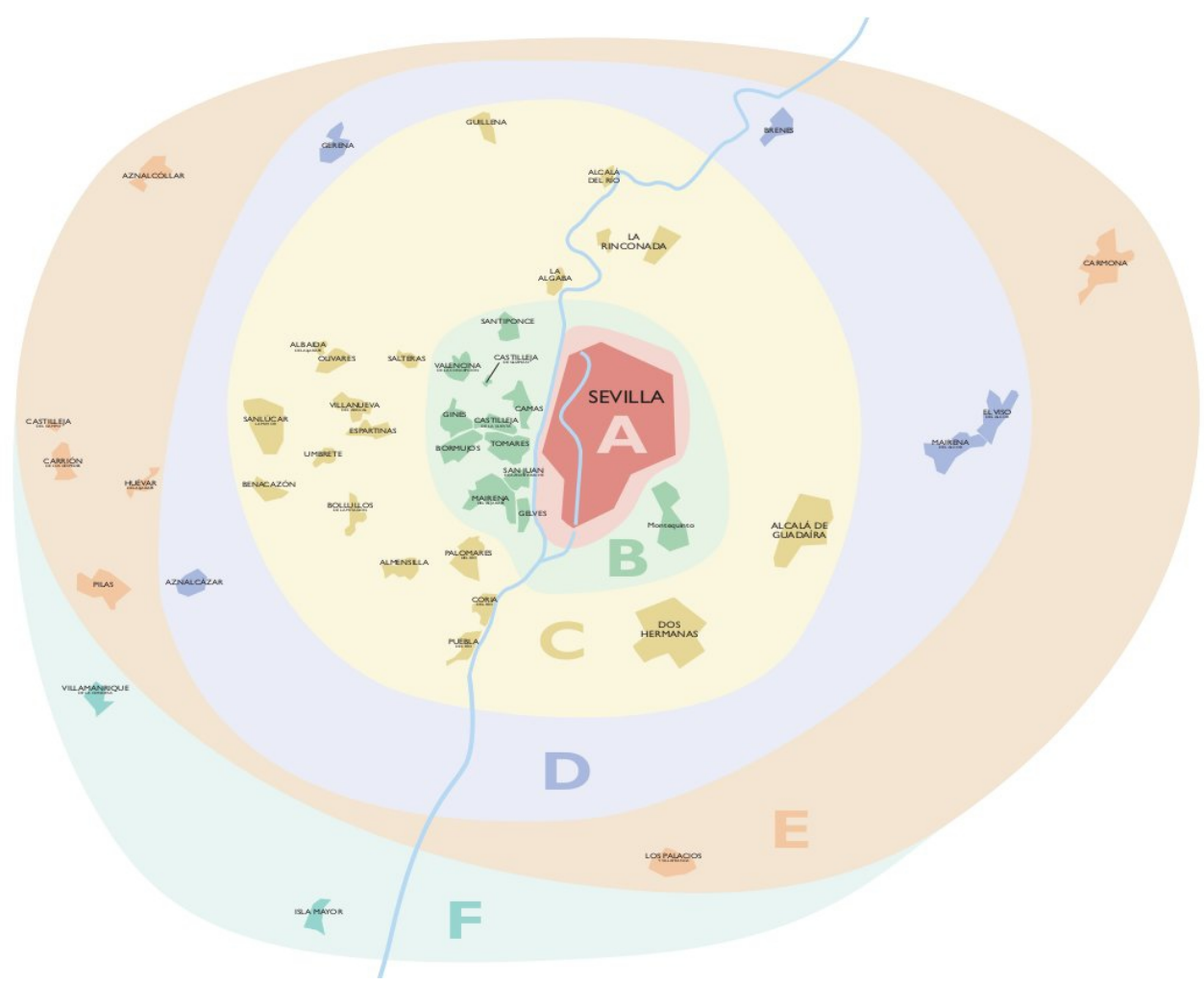




\section{ANEXO 5. AREA METROPOLITANA}

Municipios, código postal, y número de habitantes según padrón municipal 2016.

A continuación, aparecen los recursos usados para la localización de la información municipal y una tabla con los municipios que han sido utilizados en los análisis.

Para los Códigos Postales:

$\underline{\text { http://www.correos.es/ss/Satellite/site/pagina-buscador_codigos_postales/sidioma=es_ES }}$

Para Dos Hermanas:

-Ayuntamiento de Dos Hermanas.

http://www.doshermanas.es/dher/opencms/dher/portal/ayuntamiento/servicios_ciudadano/co digos_postales/

Para el número de habitantes:

Sistema de Información Multiterritorial de Andalucía (SIMA). Instituto de

Estadística y Cartografía de Andalucía (IECA). Padrón Municipal de

Habitantes. 2014.

http://www.juntadeandalucia.es/institutodeestadisticaycartografia/sima/index2.htm

\begin{tabular}{|c|c|c|}
\hline Municipio & Código postal & Población \\
\hline Alcalá de Guadaíra & 41500 & 74.404 \\
\hline Bormujos & 41930 & 20.947 \\
\hline Camas & 41900 & 26.665 \\
\hline Castilleja de Guzmán & 41908 & 2.871 \\
\hline Castilleja de la Cuesta & 41950 & 17.536 \\
\hline Dos Hermanas & $\begin{array}{l}41700 \\
41701 \\
41702 \\
41703 \\
41704 \\
41089\end{array}$ & 130.369 \\
\hline Gelves & 41120 & 9.688 \\
\hline Gines & 41960 & 13.299 \\
\hline Mairena del Aljarafe & 41927 & 43.723 \\
\hline San Juan de Aznalfarache & 41920 & 21.576 \\
\hline Santiponce & 41970 & 8.439 \\
\hline Tomares & 41940 & 24.501 \\
\hline Valencina de la Concepción & 41907 & 7.930 \\
\hline
\end{tabular}

